\title{
Relationship between Foreign Direct Investment and Economic Growth Case Study of Nepal
}

\author{
Xinfeng Yan (Corresponding author) \\ Donghua University, Shanghai 200051, China \\ Tel: 86-21-6237-3066 E-mail: yanxf@dhu.edu.cn \\ Majagaiya, Kundan Pokhrel \\ Glorious Sun School of Management, Donghua University \\ Shanghai 200051, China \\ E-mail: kundanpokhrel@yahoo.com
}

Received: February 9, $2010 \quad$ Accepted: December 20, 2010 doi:10.5539/ijbm.v6n6p242

\begin{abstract}
This study examines the serial correlation ship between foreign direct investment and economic growth of Nepal in terms of GDP for the period of 1983-2007.This study has been carried out with log and non log - values using Durbin-Watson Test and Cochrance-Orcutt method. The result shows that even though marginal effect seems to be because of presence of auto-correlation, without presence of auto-correlation FDI does not adequately describe the GDP.
\end{abstract}

Keywords: FDI, GDP, Autocorrelation

\section{Introduction}

Foreign Direct Investment Continues to play a crucial role around the world and its importance to the global economy cannot be understated. Researchers from different disciplines are pursuing their work in FDI to better understand, explain and report the most recent findings. Flow of Foreign Direct Investment has grown faster over recent past. Higher flows of Foreign Direct Investment over the world always reflect a better economic environment in the presence of economic reforms and investment-oriented policies. As the forces of globalization have continued to integrate the world economy, foreign direct investment (FDI) has proliferated.

FDI in developing countries like Nepal seems to be a new terminology and issue. However, historical records and literature presents its long history stating that FDI is not a new phenomenon.

The inflow of FDI in Nepal began in the early 1980s through the gradual opening up of the economy. From 1980 to 1989 , FDI inflows to Nepal were minimal with an annual average of US\$500,000. FDI inflow showed a distinct acceleration during the 1990s averaging US\$ 11 million per annum during 1990-2000, peaking at US\$ 23 million in 1997 (UNCTAD, 2003b and 2006). This was primarily due to Nepal's more liberal trade policies, which comprised tariff rate reductions, the introduction of a duty drawback scheme, the adoption of a current account convertibility system and liberalization of the exchange rate regime. A reversal in the rising trend took place from the beginning of the 2000s. All in all, FDI inflow is the lowest in Nepal even when compared with other landlocked countries (World Bank, 2003)

\section{Literature Review}

Proponents of foreign direct investment such as development institutions, economists, academics and policy makers argued that foreign direct investment ensures efficient allocation of resources as compared to other forms of capital inflows. However, some literature suggests that the FDI inflows have a positive impact on economic growth of host countries and other literature suggests not at all. Although a large volume of econometric literature includes the impacts of FDI on economic growth in developing countries, not enough studies has been carried out on the question of serial correlation between them. Though there have been a few studies on the related topic for academic and non-academic purposes but these studies do not reflect the exact serial relation. 
Bengoa and Sanchez-Robles showed that FDI is positively correlated with economic growth, but host countries require human capital, economic stability and liberalized markets in order to benefit from long term FDI inflows. Where as Durham fails to identify a positive relationship between FDI and Economic growth in terms of GDP, but suggest that effects of FDI are contingent on the "absorptive capability of host countries" According to Balasuramanyam, Salisu and Spasford and De Mello; FDI is a capital bundle of capital stock, knowhow and technology and can augment the existing stock of knowledge in the recipient economy through labor training skill acquisition and diffusion and the introduction of alternative management practices and organizational arrangement. Unfortunately, the impact of FDI on growth remains more contentious in empirical than in theoretical studies. While some studies observe a positive impact of FDI in economic growth, other detects a negative relationship between these two variables.

\section{Analytical Framework and Methodology}

The most celebrated test for detecting serial correlation is developed by Durbin and Watson and is defined by,

$$
d=\frac{\sum_{t=2}^{N}\left(e_{t}-e_{t-1}\right)^{2}}{\sum_{t=1}^{N} e_{t}^{2}}
$$

which is simply the ratio of sum of squared differences in successive residuals to the residual sum of square (RSS) and can be written as;

$$
d \cong 2(1-\rho)
$$

Here in equation 2 we define $\rho=\frac{\sum e_{t} e_{t-1}}{\sum e_{t}{ }^{2}}$ and assume $\sum e_{t}{ }^{2} \& \sum e_{t-1}{ }^{2}$ are

approximately equal as they differ by only one observation.

Since $-1 \leq \rho \leq 1$, equation 2 implies that

$$
0 \leq d \leq 4
$$

Decision can be made regarding the presence of positive or negative correlation with this lower and upper bounds. Here in eq. 2

$$
\begin{aligned}
& \text { If } \rho=0, \mathrm{~d}=2 \quad \text { implies there is no serial correlation. } \\
& \text { If } \rho=+1, \mathrm{~d}=0 \quad \text { implies perfect positive correlation. } \\
& \text { If } \rho=-1, \mathrm{~d}=4 \quad \text { implies perfect negative correlation. }
\end{aligned}
$$

It is important to know that if the estimated value lies between lower limit and upper limit we can not predict whether auto correlation exit or not. That means this is the case of indecision. To overcome this drawback, Cochrance - Orcutt method is carried out.

An alternative to estimate $\rho$ from Durbin-Watson $\mathrm{d}$ is the frequently used Cochrane-Orcutt method that uses the estimated residuals $\mathrm{e}_{\mathrm{t}}$ to obtain information about the unknown $\rho$.

To explain the method, consider the two variable models:

$$
Y_{t}=\beta_{1}+\beta_{2} X_{t}+u_{t}
$$

And assume that $u_{t}$ is generated by the AR (1) scheme, then;

$$
u_{t}=\rho u_{t}-1+\varepsilon_{t}
$$

The data used in this study is aggregate annual time series at constant prices for gross domestic product (GDP) and total net inflows for foreign direct investment (FDI) covering the period of 1983-2007 in 25 pairs of observations. The data was extracted from the International Monetary Fund, World economic Outlook and World Investment Report, Fact book of various years and Econ- stat.

\section{(Insert Fig.1 here)}




\section{Empirical results}

The estimated simple linear regression model of GDP on FDI along with t-statistic in parenthesis is,

$$
\begin{aligned}
& \text { UBP } \frac{-4100.39}{(4.4 \%)}+\frac{64.16 \mathrm{FDI}}{(1.5 \% 4)} \\
& \mathrm{R}^{2}=0.0 \mathrm{~S}, \mathrm{~K}^{2}=0.054, \quad \mathrm{~F}=2.4 \% 6, \text { DW statistic }=0.3804
\end{aligned}
$$

The results obtained from the simple linear regression model of GDP on FDI are presented in table.1

The estimated log linear regression model of GDP on FDI along with t-statistic in parenthesis is

$$
\begin{array}{lll}
\log U D P & -0.49 & -2.03 \log \text { TDI } \\
(-0.25) & (2.05)
\end{array}
$$

$$
\mathrm{R}^{2}=0.144, \quad \mathrm{~K}^{2}=0.11, \quad \mathrm{~F}=4.21, \quad \mathrm{DW} \text { statistic }=0.545
$$

The results obtained from the log linear regression model of GDP on FDI are presented in table.2

The linear Cochrane-Orcutt iterative procedure history is presented in table. 3

The log linear Cochrane-Orcutt iterative procedure history is presented in table. 4

The estimated log linear Cocharane-Orcutt iterative regression model of GDP on FDI along with t-statistic in parenthesis is

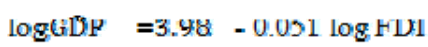

$$
\begin{aligned}
& \text { (10.63) } \quad(-0.281) \\
& \mathrm{R}^{2}=0.0034, \quad \mathrm{R}^{2}=-0.083, \quad \mathrm{~F}=0.079, \quad \mathrm{DW} \text { statistic }=1.309
\end{aligned}
$$

The results obtained from the log linear Cocharane-Orcutt iterative regression model of GDP on FDI are presented in table.5

\section{Result and Discussion}

From the simple linear regression model of GDP on FDI, value of $\mathrm{R}^{2}$ indicates that 9 percent of variation in GDP is explained by FDI. The calculated $\mathrm{F}=2.476$ indicates that the regression model is not significant at 1 percent level of significance because significance $\mathrm{F}$ value $0.128>0.01$.

The marginal effect of FDI on GDP is 64.16. This means that an increase of unit on FDI is expected to increase GDP, on average, by 64.16 units. The t- statistic for constant is significant at $1 \%$ level of significance and FDI coefficient is not significant at 1 percent level, as the $p$-value for constant ( $p$-value $=0.000)$ is less than 0.01 but $\mathrm{p}$-value for FDI coefficient ( $\mathrm{p}$-value $=0.128$ ) is greater that 0.01 .

From the estimated regression we observe that the Durbin-Watson $d$ indicates the presence of autocorrelation. For 25 observations and 1 explanatory variable the $1 \%$ Durbin- Watson table shows that $\mathrm{d}_{\mathrm{L}}=1.05$ and $\mathrm{d}_{\mathrm{U}}=1.21$, and the estimated $\mathrm{d}(0.3804)$ is below the lower critical limit $\left(\mathrm{d}_{\mathrm{L}}=1.0\right)$. Which indicates the regression equation 6 is plagued by auto correlation and we can not trust on the estimated $t$ ratios, and coefficient of determination.

From the log linear regression model of GDP on FDI, value of $\mathrm{R}^{2}$ indicates that 14.4 percent of variation in $\log$ GDP is explained by $\log$ FDI. The calculated $F=4.21$ indicates that the regression model is not significant at 1 percent level of significance because significance $\mathrm{F}$ value $0.051>0.01$.

The marginal effect of log FDI on log GDP is 2.03. This means that an increase of unit on log FDI is expected to increase $\log$ GDP, on average, by 2.03 units. Since the p-values for constant (p-value $=0.807)$ and coefficient ( $\mathrm{p}$-value $=0.051$ ) are greater than 0.01 , $\mathrm{t}$ - statistic for both constant and coefficient is not significant at 1 per cent level.

From the estimated regression we observe that the Durbin- Watson $d$ indicates the presence of autocorrelation. For 25 observations and 1 explanatory variable the $1 \%$ Durbin- Watson table shows that $\mathrm{d}_{\mathrm{L}}=1.05$ and $\mathrm{d}_{\mathrm{U}}=1.21$, and the estimated $(\mathrm{d}=0.545)$ is below the lower critical limit $\left(\mathrm{d}_{\mathrm{L}}=1.05\right)$.

From the both procedure above, we can not predict the actual relationship between the variables; so, Cochrane-Orcutt iterative procedure is carried out.

From the above Cochrane-Orcutt iterative history, iterations from 1 to 4 shows that there is positive autocorrelation as estimated DW statistic lies below the lower critical limit and iterations from 5 to 9 shows that 
we can not conclude that whether there is autocorrelation or not?; as estimated DW statistic lies between lower and upper critical limit. So, for more precise decisions regarding GDP and FDI we carried out log linear Cochrane-Orcutt iterative procedure.

The log linear Cochrane-Orcutt iterative procedure was terminated at step 3 as estimated DW statistic $(\mathrm{d}=1.309)$ shows that there is no autocorrelation.

From the log linear Cocharane-Orcutt iterative regression model of GDP on FDI, value of $\mathrm{R}^{2}$ indicates that 0.34 percent of variation in GDP is explained by FDI. Negative adjusted value of $R^{2}\left(R^{2}=0.083\right)$ indicates that the FDI does not adequately describe the GDP.The calculated $\mathrm{F}=0.079$ indicates that the regression model is not significant at 1 percent level of significance because significance $F$ value $0.781>0.01$.

The marginal effect of FDI on GDP is -0.051 . This means that an increase of unit on log FDI is expected to decrease $\log$ GDP, on average by 0.051 units. The t- statistic for FDI coefficient is not significant at 1 per cent level, since $p$-value $(=0.781)$ for FDI coefficient is greater that 0.01 . From the estimated $(d=1.309)$ shows that there is no presence of autocorrelation at $1 \%$ level of significance.

\section{Conclusion}

There was no direct way of identifying the linkage between FDI and GDP. Unavailability of necessary data was an additional constraint Therefore; the research had to be based on the secondary, which may not provide a representative picture of the overall situation of FDI and GDP in Nepal. Our result shows that even though marginal effect seems to be not significant because of presence of auto-correlation, but without presence of auto-correlation FDI does not adequately describe the GDP.

\section{References}

Agrawal P. (2000). Economic impact of foreign direct investment in south Asia. Indira Gandhi Institute of Development Research, Gen. A.K. Bombay; India.

Balasubramanyam, V.N., M. Salisu and D. Spas ford. (1996). Foreign direct investment and economic growth in EP an IS countries. Econ. J., 106: 92-105.

Choe, J.I. (2003). Do foreign direct investment and gross domestic investment promote economic growth? Rev. Develop. Econ, 7:44-57.

Gujarati, D. (2003). Basic Econometrics. $4^{\text {th }}$ Ed $^{\mathrm{n}}$., McGraw-Hill, New York. 1002pp ISBN: 0-07-233542-4.

Noorzoy, M.S. (1980). Flows Direct Investment and their effects on US domestic investment. Econ. Lett., 5: 311-317.

[Online] Available: http://www.d21.org

[Online] Available: http://www.econstats.com/weo/CAFG.htm

[Online] Available: http://www.imf.org

[Online] Available: http://www.nrb.org

[Online] Available: http://www.unctad.org;

[Online] Available: http://www.undp.org

[Online] Available: http://www.worldbank.org

[Online] Available: http://www.wto.org

Table 1.

\begin{tabular}{|c|c|c|c|c|c|}
\hline R- square & Adj.R -square & F-statistics & Intercept & FDI & Significance F \\
\hline 0.090117206 & 0.053721894 & 2.476066 & 4100.391265 & 64.15577932 & 0.128162616 \\
\hline
\end{tabular}

Table 2.

\begin{tabular}{|l|c|c|l|l|c|}
\hline R- square & Adj.R -square & F-statistics & Intercept & FDI & Significance F \\
\hline 0.144291687 & 0.110063354 & 4.215563 & -0.49357304 & 2.029842082 & 0.0506583 \\
\hline
\end{tabular}


Table 3.

\begin{tabular}{|c|c|c|c|c|}
\hline Iteration & Rho & SE Rho & DW & MSE \\
\hline 1 & .71441186 & .14283086 & .3804767 & 497977.96 \\
\hline 2 & .86960371 & .10078636 & .7622389 & 228920.14 \\
\hline 3 & .91898258 & .08048577 & .9352987 & 175261.52 \\
\hline 4 & .94582775 & .06627275 & 1.0272812 & 152490.94 \\
\hline 5 & .95840176 & .05826165 & 1.0632767 & 143364.99 \\
\hline 6 & .96248702 & 05538454 & 1.0729413 & 140610.57 \\
\hline 7 & .96347016 & .05466765 & 1.0750664 & 139963.10 \\
\hline 8 & 96367909 & .05451399 & 1.0755070 & 139826.27 \\
\hline 9 & .96372208 & .05448232 & 1.0755971 & 139798.15 \\
\hline
\end{tabular}

Table 4.

\begin{tabular}{|c|c|c|c|c|}
\hline Iteration & Rho & SE Rho & DW & MSE \\
\hline 1 & .68680025 & .14836686 & .545 & 0.004 \\
\hline 2 & .86809920 & .10132534 & 1.142 & 0.002 \\
\hline 3 & 90846588 & .08531553 & 1.309 & 0.001 \\
\hline
\end{tabular}

Table 5 .

\begin{tabular}{|c|c|c|c|c|c|}
\hline R- square & Adj.R -square & F-statistics & Intercept & FDI & Significance F \\
\hline 0.00342754 & -0.08323096 & 0.079 & -0.0510199 & 3.9801612 & 0.78103002 \\
\hline
\end{tabular}

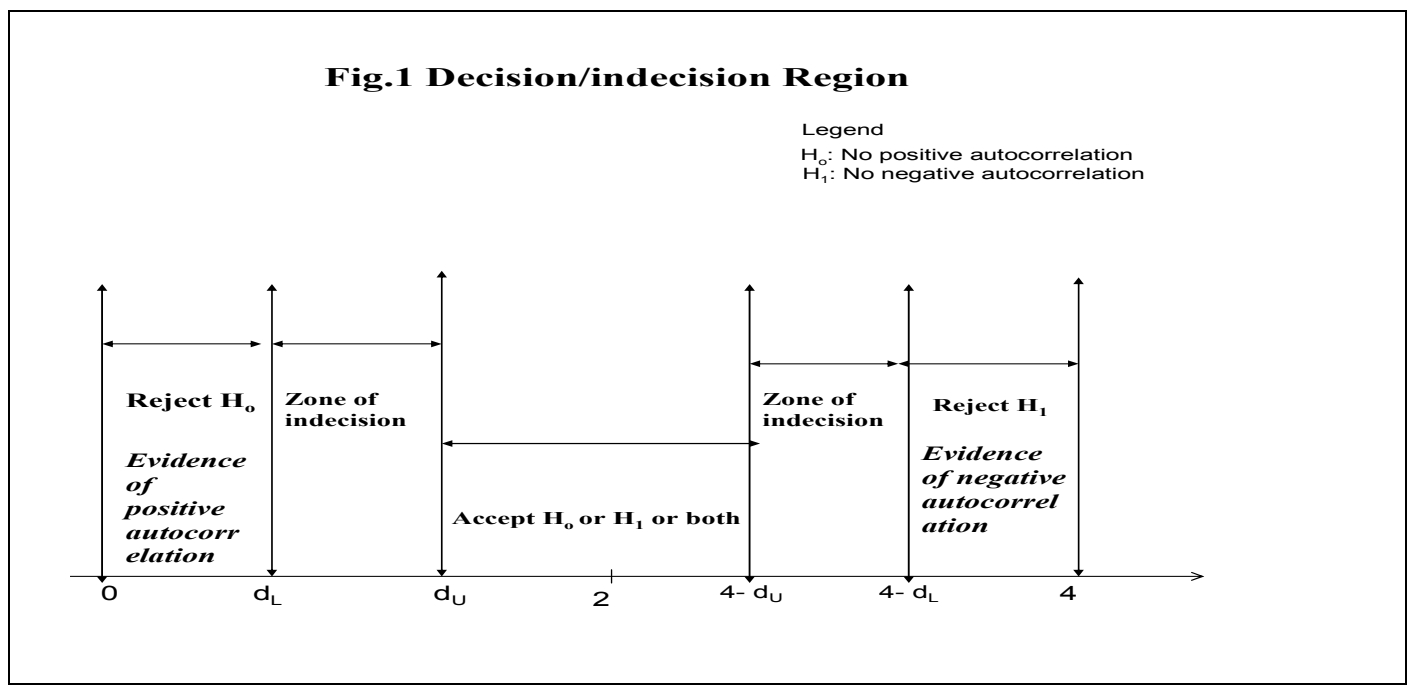

Figure 1. Description for decision / Indecision Region

(Source: Gujarati, D., 2003. Basic Econometrics. $4^{\text {th }} \mathrm{Ed}^{\mathrm{n}}$., McGraw-Hill, New York. 1002pp ISBN:

0-07-233542-4) 